\title{
Physicochemical Characteristics and HPLC Determination of Alpha-Tocopherol in Eighteen Edible Vegetable Oils Marketed in Nigeria
}

\section{Olufunmilayo Ebunoluwa Adejumo ${ }^{1}$, Elizabeth Ayodele Popoola ${ }^{1}$, Oluyemisi Adebowale Bamiro ${ }^{2}$, J ohn Olabanji Daodu ${ }^{1}$ and Olatunde J ames Olaitan ${ }^{1}$}

\author{
${ }^{1}$ Department of Pharmaceutical and Medicinal Chemistry, Faculty of Pharmacy, Olabisi Onabanjo University, \\ Sagamu Campus, Ogun state, Nigeria \\ ${ }^{2}$ Department of Pharmaceutics and Pharmaceutical Technology, Faculty of Pharmacy, Olabisi Onabanjo \\ University, Sagamu Campus, Ogun state, Nigeria
}

(Received: October 14, 2020; Accepted: March 22, 2021; Published (web): June 20, 2021)

\begin{abstract}
Eighteen brands of vegetable oils available in the local market were extracted with $n$-hexane before analysis for alpha-tocopherol by RP-HPLC method. The chromatographic separation occurred isocratically with methanol-water $[96: 4 \% \mathrm{v} / \mathrm{v}]$ at $0.9 \mathrm{ml} / \mathrm{min}$ flow rate. Tocopheryl acetate was the internal standard and alpha-tocopherol was eluted at $7.87 \mathrm{~min}$. Free fatty acids value [FFAVs], peroxide value [PV], iodine value [IV] and saponification values [SV] were determined as quality parameters. Calibration curve was linear $\left[\mathrm{r}^{2} 0.9969\right]$ and the method was precise with relative standard deviation of $0.35 \%$ and mean recovery, $87.39 \%$. Alpha-tocopherol concentration ranged from $0-9.22 \mathrm{mg} / 100 \mathrm{~g}$ with the highest in Tropical sunflower oil $[9.22 \mathrm{mg} / 100 \mathrm{~g}]$ and the lowest $[1.16 \mathrm{mg} / 100 \mathrm{~g}]$ in Laziz oil. Alpha-tocopherol was not detected in unbranded, local palm oil. The calculated percentage daily value [\% DV] of vitamin E ranged from 0$8.60 \%$. Significant difference $[\mathrm{p}<0.05]$ between $\% \mathrm{DV}$ and recommended dietary allowance [RDA] of vitamin E was observed. FFAs and PV ranged from $0.11-0.74 \%$ and $0.99-11.55 \mathrm{meq} / \mathrm{kg}$ while IV and SV ranged from 26.71-37.03 $\mathrm{g} / 100 \mathrm{~g}$ and 4.14-43.68 mg KOH/g, respectively. Seventeen samples [94\%] were found to be within the acceptable limits while one [6\%], failed for both quality parameters and $\alpha$-tocopherol test. Strict regulatory control is advocated for these oils to safeguard the public health.
\end{abstract}

Key words: Vegetable oils, physicochemical characteristics, quality assessment, $\alpha$-tocopherol, RP-HPLC

\section{INTRODUCTION}

Vitamins are organic compounds that promote and regulate essential biochemical reactions within the body, which itself is unable to synthesize these compounds hence are required in the diet in trace amounts. ${ }^{1}$ Vitamin E, a fat-soluble vitamin, which can be classified into tocopherols and tocotrienols (Figure 1) is a naturally occurring antioxidant present in some foods. Each class consists of alpha, beta, gamma and delta forms ${ }^{2}$ differing only in their chemical structures. Tocopherols differ from each

Correspondence to: Olufunmilayo Ebunoluwa Adejumo Tel.: +234 [0] 8052705549; Email: funmijumo@yahoo.co.uk

Dhaka Univ. J. Pharm. Sci. 20(1): 49-57, 2021 (June)

DOI: https://doi.org/10.3329/dujps.v20i1.54032 other by the number and position of methyl group in the phenolic part of the chromane ring. ${ }^{3,4}$ They have saturated phytyl tail while the tocotrienols have shorter unsaturated farnesyl tail with three isolated double bonds. ${ }^{5}$ Biological activities and anticancer effects for tocopherols have been reported. ${ }^{6,7}$ Alphatocopherol is an important antioxidant and essential micronutrient that protects the body from degenerative diseases. Vitamin $\mathrm{E}$ has been reported to protect cell wall fatty parts; prevent oxidation of polyunsaturated fatty acids, prevent nerves and muscle degeneration aside reducing oxygen requirement of muscles. ${ }^{1}$ 


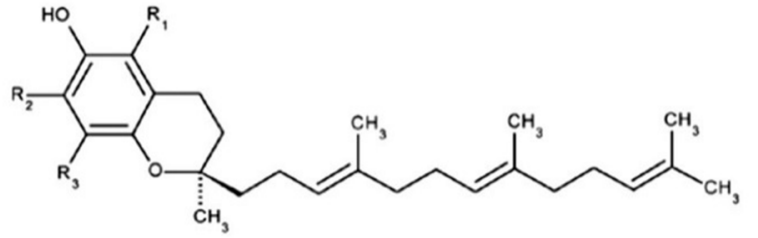

Tocopherols Alpha $(\alpha): \mathrm{R}_{1}=\mathrm{CH}_{3}, \mathrm{R}_{2}=\mathrm{CH}_{3}, \mathrm{R}_{3}=\mathrm{CH}_{3}$ $\operatorname{Gamma}(\gamma): \mathrm{R}_{1}=\mathrm{H} ; \mathrm{R}_{2}=\mathrm{CH}_{3} ; \mathrm{R}_{3}=\mathrm{CH}_{3}$

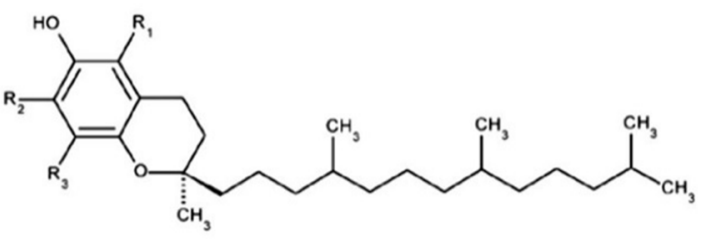

Tocotrienols

Beta $(\beta): \mathrm{R}_{1}=\mathrm{CH}_{3}, \mathrm{R}_{2}=\mathrm{H} ; \mathrm{R}_{3}=\mathrm{CH}_{3}$ Delta $(\delta): \mathrm{R}_{1}=\mathrm{H} ; \mathrm{R}_{2}=\mathrm{H} ; \mathrm{R}_{3}=\mathrm{CH}_{3}$

Figure 1. Chemical structure of tocopherols and tocotrienols.

Vegetable oils are the major dietary source of vitamin $\mathrm{E}^{8}$, with variable isomers according to oil identity ${ }^{9}$, which decreases the risk of cardiovascular diseases and cancer. ${ }^{10}$ The presence of tocopherols in vegetable oils, protect such oils from oxidation and consequently aiding oil stability. ${ }^{11}$ The quality of oils is indicated by some physicochemical properties like appearance, free fatty acids, saponification value, fatty acids, iodine value, and peroxide value, specific gravity, unsaponifiable value etc. ${ }^{12,13}$ whose evaluation and specific values provide an indication of both the nutritive value and physical oil quality. Oil exposure to moisture, light or heat can alter some of the quality indicators and the extent of instability or spoilage depends largely on the condition and temperature of storage, as well as the duration of exposure. $^{14,15}$ Oxidative stability of oils is an important indicator in the determination of oil quality and shelf life. ${ }^{16}$

Analytical methods that have been described for the determination of tocopherols and tocotrienols in oils include saponification, followed by analysis with high performance liquid chromatography (HPLC) and gas chromatography (GC). ${ }^{17-21}$ Analysis of tocopherols in vegetable oils by HPLC could be achieved by normal (NP) or reverse-phase (RP) columns. ${ }^{22-25}$ Retention time reproducibility, fast equilibration and robustness of RP column over other stationary phases $^{26}$ and preservation of the environment by the solvent systems used in RPHPLC are more preferable than those used in NPHPLC. ${ }^{27}$ For these reasons, RP-HPLC is preferred over NP-HPLC systems. Additionally, isocratic or gradient elution with fluorescence, electrochemical and ultraviolet-visible (UV-Vis) detectors ${ }^{28-30}$ may be employed. Other detectors include evaporative light scattering (ELSD) and amperometry. ${ }^{31}$

HPLC is currently the most widely used method of quantitative analysis in the pharmaceutical industry and pharmaceutical analysis laboratory. GC is normally disregarded because these compounds are non-volatile, hence will require derivatization prior to their quantification. ${ }^{24}$

Different brands of vegetable oils and palm oils are either being produced or imported and there is need to screen these vegetable oils to confirm the labelled content of $\alpha$-tocopherol with the tested results as well as to assess their quality and suitability for human consumption.

Thus, the aim of this study was to evaluate the physicochemical characteristics of eighteen brands of vegetable oils marketed in Nigeria using established protocols and determine their $\alpha$-tocopherol content using reversed-phase high performance liquid chromatography (RP-HPLC) with UV detection.

\section{MATERIALS AND METHODS}

Materials. Eighteen brands of vegetable oils were purchased from various markets in Lagos and Sagamu, Nigeria (Table 1). Reagents include HPLC grade methanol (Sigma-Aldrich, USA), DL $\alpha$ tocopherol (Supelco), tocopherol acetate and hexane (Sigma-Aldrich, USA). Distilled water was obtained from Fidson Pharmaceutical Industry while all other chemicals and reagents were of analytical grades. 
Chromatographic conditions. The HPLC system was an Agilent 1100 HPLC series, USA equipped with a main controlling unit, quaternary pump, online degasser, waters $\mathrm{x}$-bridge $\mathrm{C} 18$ column (100 x $4.6 \mathrm{~mm}$ ID, 5 um particle size), with $20 \mu \mathrm{l}$ injector loop and UV-Vis chem-station software detector. Mobile phase was made up of HPLC grade methanol and water (96:4) and ran at a flow rate of $0.9 \mathrm{~mL} / \mathrm{min}$ with temperature kept at $35^{\circ} \mathrm{C}$. The detector wavelength was set at $292 \mathrm{~nm}$.

Table 1. Details of vegetable oil samples.

\begin{tabular}{llllc}
\hline $\begin{array}{l}\text { Sample } \\
\text { number }\end{array}$ & Name of brand & Ingredient Source & $\begin{array}{c}\text { Date of } \\
\text { manufacture }\end{array}$ & Expiry date \\
\hline 1.0 & Devon Kings vegetable oil & Palm olein [fraction of palm oil] & $12 / 07 / 16$ & $12 / 07 / 17$ \\
2.0 & Sunola soya oil & Seeds of Glycine max [soy bean] & $09 / 2015$ & $09 / 2017$ \\
3.0 & Golden Penny pure soya oil & Glycine max [soy bean] & $28 / 08 / 15$ & $28 / 08 / 16$ \\
4.0 & Adan soybean oil & Glycine max [soy bean] & $28 / 05 / 15$ & $27 / 05 / 17$ \\
5.0 & Mamador pure vegetable oil & Palm olein [fraction of palm oil] & $21 / 10 / 15$ & $21 / 10 / 16$ \\
6.0 & Power oil & Palm olein [fraction of palm oil] & $21 / 03 / 16$ & $21 / 03 / 17$ \\
7.0 & Lesieur vegetable oil & Palm olein [fraction of palm oil] & $05 / 2015$ & $05 / 17$ \\
8.0 & Laziz vegetable oil & Palm olein [fraction of palm oil] & $09 / 11 / 15$ & $09 / 11 / 16$ \\
9.0 & Mazola corn oil & Embryo of Zea mays & $25 / 12 / 15$ & $25 / 12 / 16$ \\
10.0 & Zok cotton seed oil & Seeds of Gossypium spp. & $27 / 07 / 15$ & $26 / 07 / 17$ \\
11.0 & Tropical sunflower oil, & Seeds of Helianthus annus & - & $09 / 2017$ \\
12.0 & Borges extra virgin olive oil & Fruits of Olea europaea & - & $10 / 2017$ \\
13.0 & Classic olive oil & Fruits of Olea europaea & - & $10 / 2017$ \\
14.0 & Goya Spanish olive oil [plastic] & Fruits of Olea europaea & - & - \\
15.0 & Goya extra virgin olive oil [bottle] & Fruits of Olea europaea & - & $10 / 2017$ \\
16.0 & Groundnut oil Kuli-kuli [local] & Arachis hypogaea & - & - \\
17.0 & Palm oil [unbranded] & Elaeis-guineensis [fruit of oil palm] & - & - \\
18.0 & Rodi palm oil & Elaeis-guineensis [fruit of palm oil] & $25 / 0915$ & $25 / 09 / 16$ \\
\hline
\end{tabular}

Preparation of standards. DL- $\alpha$-tocopherol (10 $\mathrm{mg}$ ) was dissolved with ethanol (96\%) and made up to $100 \mathrm{~mL}$ in a volumetric flask to form the stock solution of $0.1 \mathrm{mg} / \mathrm{ml}$. It was protected from light by wrapping with aluminum foil. Different concentrations $(1.0 \mu \mathrm{g} / \mathrm{ml}, 2.5 \mu \mathrm{g} / \mathrm{ml}, 5 \mu \mathrm{g} / \mathrm{ml}, 10$ $\mu \mathrm{g} / \mathrm{ml} \& 20 \mu \mathrm{g} / \mathrm{ml})$ were then prepared through various dilutions. Each standard solution was filtered before being injected into the HPLC (Agilent 1100 HPLC series, USA). Tocopheryl acetate solution $(300 \mu \mathrm{g} / \mathrm{ml})$ was used as internal standard. Each run lasted 12 minutes. Data was collected by Agilent chromatograph automated chem. station software. Peak area was plotted against concentration to generate the calibration curve. Linearity was determined from the correlation coefficient (r) of the standard plot.
Oil extraction and determination of $\alpha$ tocopherol content. Each oil sample [1 g] was weighed into a $10-\mathrm{mL}$ volumetric flask and made up to volume with hexane. $200 \mu \mathrm{L}$ was taken and mixed with $940 \mu \mathrm{L}$ of methanol and $60 \mu \mathrm{L}$ of internal standard $(300 \mu \mathrm{g} / \mathrm{ml}$ stock solution) in an ultracentrifuge bottle. It was centrifuged at $4000 \mathrm{rpm}$ for 5 minutes. Tocopherol analysis was carried out by RP-HPLC with an Agilent 1100 HPLC series, USA using the method of Gimeno et al. ${ }^{22}$ with major modifications to column temperature, flow rate and dilution factor. $20 \mu \mathrm{L}$ of each prepared sample was injected into the HPLC previously described using the conditions specified under chromatographic procedures.

Physicochemical analysis. Physicochemical parameters used in evaluating the quality of vegetable oils such as Acid value (AV), Peroxide value (PV), 
Iodine value (IV) and Saponification value (SV) were determined by established methods. ${ }^{34,37,38,46}$

Relationship between recommended daily allowance (RDA) and percentage daily value
(\%DV). Serving size of oils analysed according to labeled claim was $14 \mathrm{~g} /$ serving size. RDA and \% DV were calculated using the formula ${ }^{46}$ shown below:

$$
m g / \text { serving }=\frac{\operatorname{conc}\left(\frac{m g}{100 g} \text { of oil }\right) \times \text { servingsize }}{100}
$$

\section{RESULTS AND DISCUSSION}

Physicochemical evaluation. Table 2 shows the results for the physicochemical characteristics: peroxide, free fatty acid, iodine, and saponification values of the analyzed vegetable oils.

Peroxide value. The peroxide value is used to determine the extent of rancidity of oils during storage, therefore, it can be used as an indicator in determining stability of fats and oils. ${ }^{36}$ It is primarily used to determine the oxidation of lipids. ${ }^{37}$ The peroxide results ranged from $0.99-11.55 \mathrm{mEq} / \mathrm{kg}$ as presented in Table 2. However, the acceptable limit of peroxide value for edible oils is $10 \mathrm{mEq} / \mathrm{kg} .^{32,38}$ Sample number 17 had the highest value of 11.55 $\mathrm{mEq} / \mathrm{kg}$ which was not within the official limit. Sample number 16 was also high in peroxide value, though it was within the acceptable limit. These high values indicate the extent of rancidity due to lipid oxidation. This could have been due to storage or "age", since there were no labels on the oil, to indicate the date of manufacture/preparation.

Table 2. Saponification, Free fatty acid, peroxide, Iodine, and tocopherol values of different oils.

\begin{tabular}{lccccc}
\hline $\begin{array}{l}\text { Sample } \\
\text { number }\end{array}$ & $\begin{array}{c}\text { Peroxide value } \\
{[\mathrm{mEq} / \mathrm{Kg}]}\end{array}$ & $\begin{array}{c}\text { Free fatty } \\
\text { acid value }[\%]\end{array}$ & $\begin{array}{c}\text { Iodine value } \\
{[\mathrm{g} / 100 \mathrm{~g}]}\end{array}$ & $\begin{array}{c}\text { Saponification value } \\
{[\mathrm{mgKOH} / \mathrm{g}]}\end{array}$ & $\begin{array}{c}\text { Alpha tocopherol } \\
(\mathrm{mg} / 100 \mathrm{~g})\end{array}$ \\
\hline 1.0 & 2.76 & 0.17 & 33.85 & 17.94 & 5.42 \\
2.0 & 2.27 & 0.14 & 37.00 & 11.10 & 2.06 \\
3.0 & 0.99 & 0.19 & 36.66 & 15.03 & 2.89 \\
4.0 & 1.00 & 0.16 & 36.34 & 4.71 & 2.03 \\
5.0 & 2.24 & 0.17 & 30.61 & 19.72 & 3.04 \\
6.0 & 1.74 & 0.16 & 35.59 & 19.32 & 2.70 \\
7.0 & 3.26 & 0.14 & 35.15 & 15.78 & 4.73 \\
8.0 & 1.75 & 0.11 & 34.03 & 20.01 & 1.16 \\
9.0 & 1.49 & 0.14 & 34.47 & 32.60 & 4.67 \\
10.0 & 1.76 & 0.11 & 36.78 & 15.80 & 3.46 \\
11.0 & 2.25 & 0.17 & 37.03 & 4.14 & 9.22 \\
12.0 & 1.99 & 0.11 & 35.83 & 14.57 & 3.78 \\
13.0 & 2.01 & 0.11 & 35.52 & 34.00 & 3.49 \\
14.0 & 1.74 & 0.13 & 34.84 & 28.44 & 3.18 \\
15.0 & 1.49 & 0.14 & 35.14 & 24.72 & 4.97 \\
16.0 & 8.03 & 0.33 & 34.18 & 37.40 & 3.34 \\
17.0 & 11.55 & 0.74 & 26.71 & 43.68 & 0 \\
18.0 & 3.66 & 0.27 & 28.75 & 39.92 & 2.77 \\
\hline
\end{tabular}


Free fatty acid value (FFAV). Free fatty acid is due to hydrolysis of fats and oils which may be promoted by oil's reaction with moisture. ${ }^{39}$ Values obtained for free fatty acid ranged from $0.11-0.74 \%$ as presented in Table 2. The acceptable limit for FFA according to AOAC is $0.6 \%{ }^{33}$ while other samples were found to be within the acceptable limits. Sample number 17 , the unbranded palm oil had an elevated FFA value of $0.74 \%$, which is above the acceptable limit for edible oils. ${ }^{32,38}$ This indicates that hydrolytic rancidity and oxidative degradation might have occurred in sample 17, which could have been due to exposure to atmospheric moisture. This result also correlated with the peroxide value $[10 \mathrm{mEq} / \mathrm{kg}$ ] obtained for the same sample that was above recommended limit.

Iodine value. Iodine value is a measure of the degree of unsaturation of oils and fats. ${ }^{34}$ Results for iodine value are presented in Table 2 and it ranged from 26.71-37.03 g/100 g. High iodine values indicates high level of unsaturation in the oils. Sample 11 (Tropical Sunflower oil) had the highest iodine value of $37.03 \mathrm{~g} / 100 \mathrm{~g}$, an indication that it contains the most unsaturated fatty acids.

Saponification value. Saponification value is an index of average molecular mass of free fatty acid. ${ }^{40}$ The saponification values ranged from 4.14-43.68 mg
$\mathrm{KOH} / \mathrm{g}$ (Table 2). These values are below the official limit of $186-205 \mathrm{mgKOH} / \mathrm{g}$ specified by SON. ${ }^{38}$ Low saponification value is an indication that the oil samples will not be suitable for soap making.

\section{Quantification of $\alpha$-tocopherol in oil samples}

Standard calibration. The calibration curve of the standard is presented in Figure 2. The standard DL- $\alpha$-tocopherol eluted at a retention time of $7.8 \mathrm{~min}$ and showed an acceptable linearity with a correlation coefficient of 0.997 in the concentration range studied. Tocopheryl acetate, the internal standard eluted at $10.1 \mathrm{~min}$.

HPLC determination of $\boldsymbol{\alpha}$-tocopherol. The chromatogram of DL- $\alpha$-tocopherol and tocopherol acetate is presented in Figure 3

The elution time of dl- $\alpha$-tocopherol was different from the elution time of tocopherol acetate; hence they were well separated without interference. The elution time was used in determining the peak of the $\alpha$-tocopherol in the vegetable oils studied, while the peak area was used in calculating the concentration of the $\alpha$-tocopherol in the various oil samples. Modifications made to the method of Gimeno et $\mathrm{l}^{22}$ allowed for better peak separation

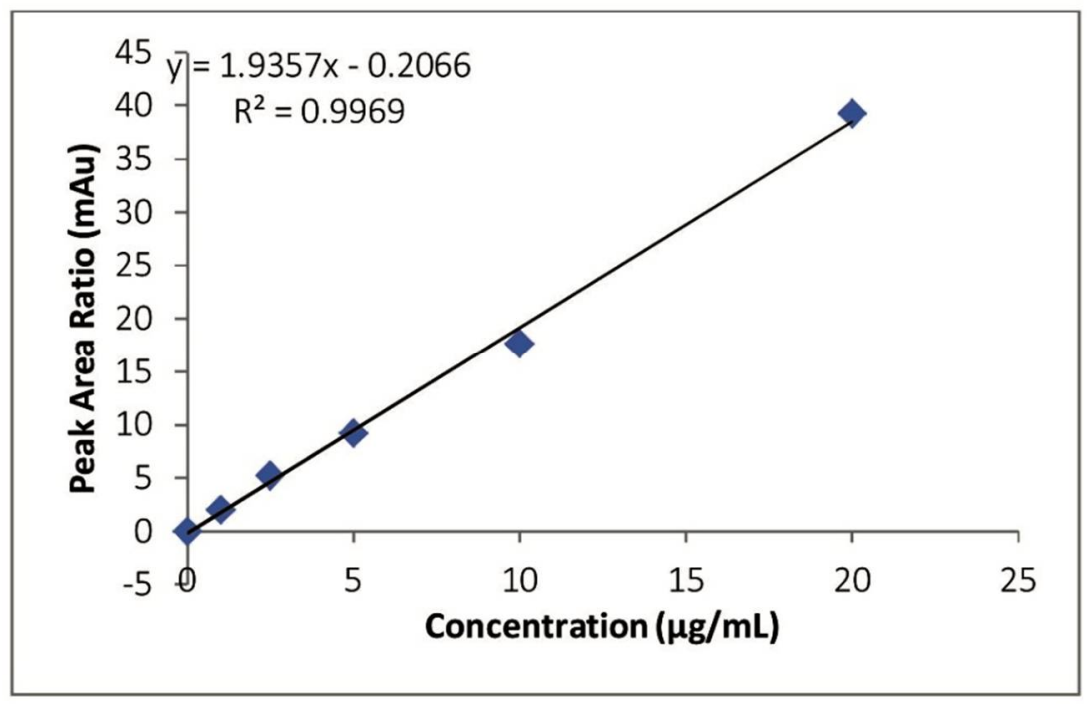

Figure 2. HPLC calibration curve for DL-alpha tocopherol 


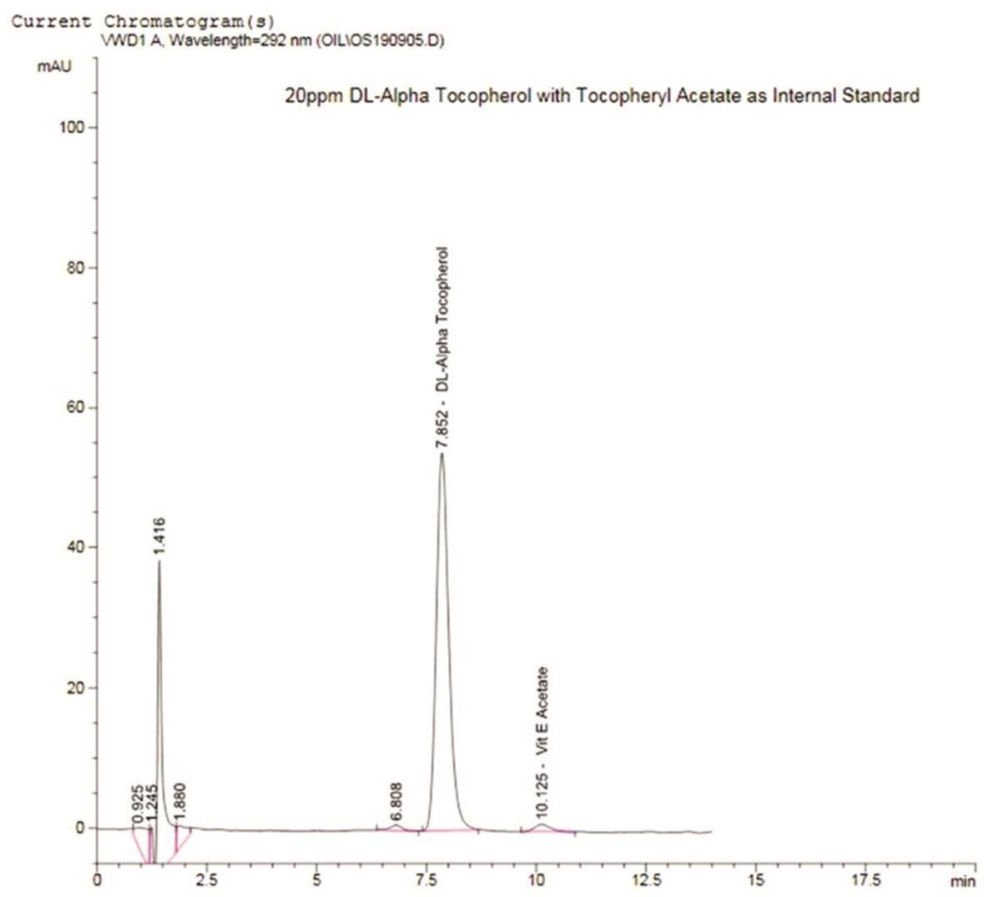

Figure 3. The chromatogram of DL- $\alpha$-tocopherol and tocopherol acetate.

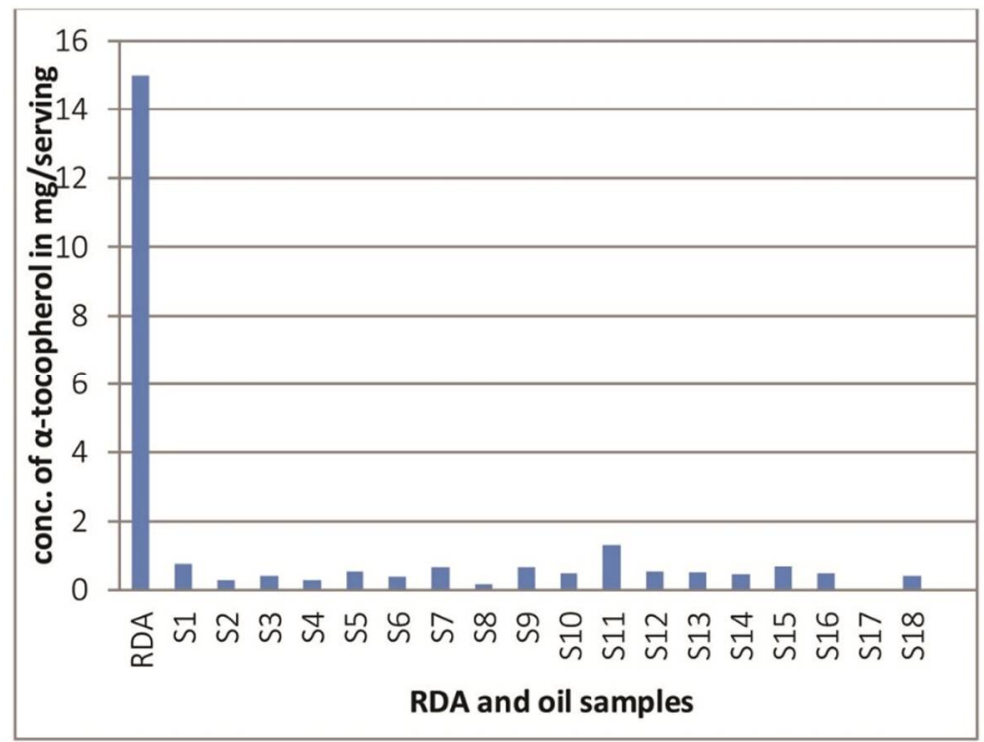

Figure 4. Relationship between daily requirement of vitamin E and RDA

and longer elution time a result of lower column temperature and flow rate. The results of the concentrations are presented in Table 2. Alphatocopherol values obtained were in the range of 0 $9.22 \mathrm{mg} / 100 \mathrm{~g}$. Tocopherols are phenolic potent natural antioxidants that prevent rancidity of oils during storage and thus increase the shelf-life of edible oils. ${ }^{41}$ Tropical sunflower oil was the richest in alpha-tocopherol with a concentration of 9.22 $\mathrm{mg} / 100 \mathrm{~g}$ while the lowest $[1.16 \mathrm{mg} / 100 \mathrm{~g}]$ was found 
in Laziz vegetable oil. This result was consistent with the previous study which reported that sunflower oil was the richest in alpha-tocopherol. ${ }^{42}$ Sample 17, the unbranded palm oil had no detectable $\alpha$-tocopherol. This could be responsible for the high presence of free fatty acids and peroxide value obtained for sample 17. The presence and importance of vitamin $E$ in these oil samples cannot be overemphasized consequent of the effect of its absence and oxygenated decomposition products on human health including membrane damage, cardiac diseases, ageing, cancer and other degenerative diseases. Thus, oil quality and its stability are very important for both consumers and application industries alike. ${ }^{43}$ Results from this study suggests that most [94\%] of the sampled vegetable oils in the south-west Nigerian market meet the recommended standards of quality test for edible oils and this is in agreement with some previous studies. $^{44}$

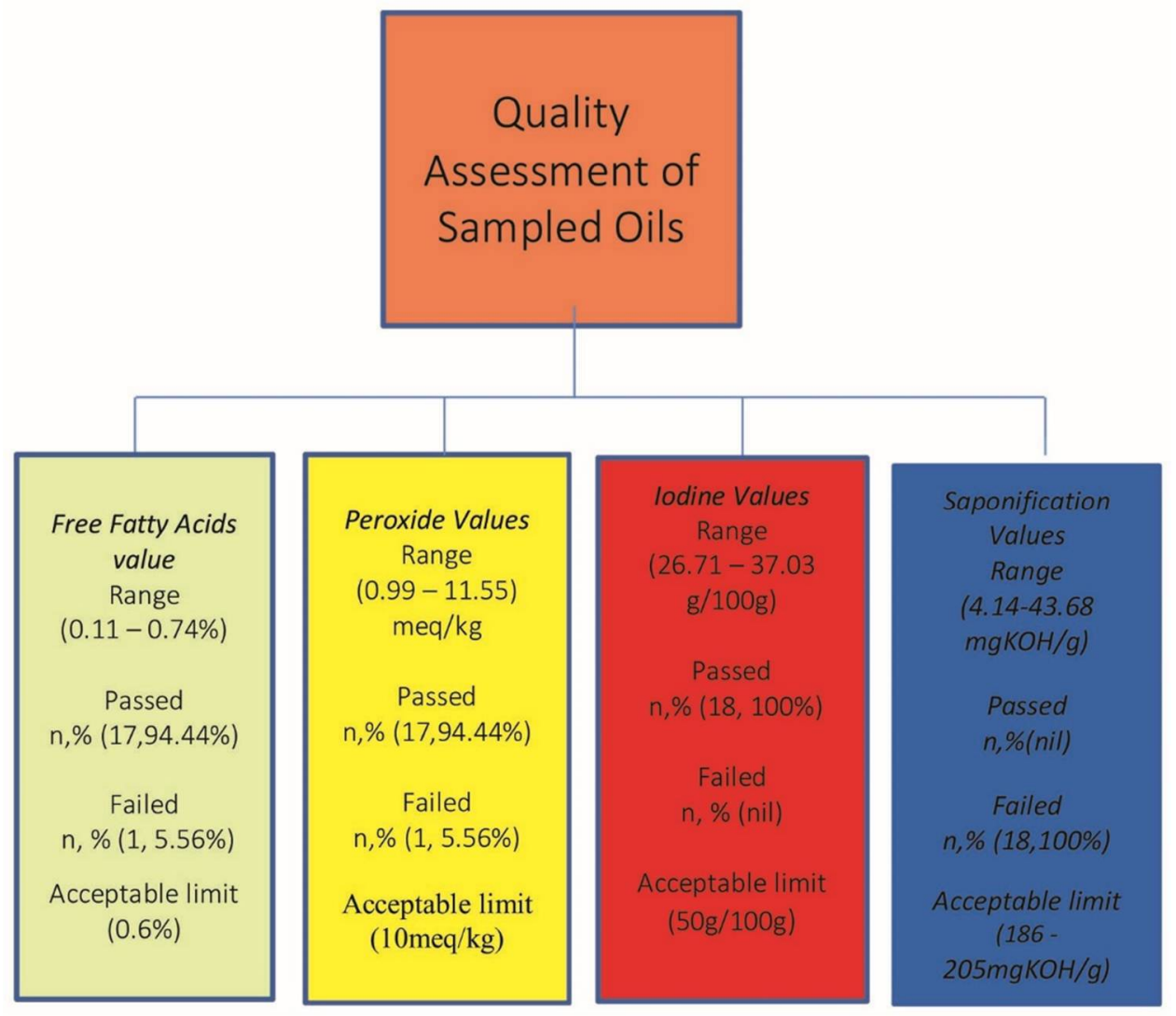

Figure 5. Summary of physicochemical parameters for oil samples used in the study

The recommended daily allowance for vitamin $\mathrm{E}$ for healthy individuals of aged 14 years and above is $15 \mathrm{mg}$ of $\alpha$-tocopherol. ${ }^{45}$ A food is considered a source of vitamin $\mathrm{E}$ if the percentage daily value [\%DV] is greater than 5\% of Recommended Daily Allowance $[R D A] .{ }^{46}$ Figure 4 shows the relationship between daily requirement of vitamin $\mathrm{E}$ and RDA which ranged from 0-1.29 mg/serving while Figure 5 outlines a summary of the physicochemical characteristics of the oil samples. Percentage daily value $[\% \mathrm{DV}]$ ranged from $0-8.60 \%$.

Tropical sunflower oil (sample 11) and Devon Kings vegetable oil (sample 1) had \% DV of $8.60 \%$ and $5.07 \%$, respectively. Therefore, samples 11 and 1 could be considered food sources of vitamin E. Other samples could not be judged as food sources of vitamin $\mathrm{E}$ because of the low \% DV observed. Factors such as fruit or seeds quality, extraction 
systems and refining procedures ${ }^{26}$ could have influenced the concentration of alpha-tocopherol in these oils aside improper storage in transparent bottles and direct exposure to sunlight in all commercial markets. ${ }^{13}$

\section{CONCLUSIONS}

The reversed-phase high performance liquid chromatography used was a good method and linear in the calibration range studied for the quantitative assessment of $\alpha$-tocopherol in the vegetable oils. Seventeen oil samples [94\%] fell within acceptable limits for edible oils while one [6\%], failed both quality and $\alpha$-tocopherol test; hence may be unsuitable for human consumption. Strict regulatory control and quality assessment is advocated for these oils to safeguard public health.

\section{ACKNOWLEDGEMENTS}

The authors express profound appreciation to Mr. Ndimele of the Department of Pharmaceutical and Medicinal Chemistry Laboratory, Olabisi Onabanjo University; Mr. Olumide Taiwo of Fidson Pharmaceuticals Industry PLC and Mr. Javis Mpock of Hydrochrom Laboratory, Nigeria for their various contributions both technical and instrumental towards this study. Also, we thank Dr Pius Fasinu of the University of Mississippi, USA for his efforts towards getting the reference standard.

\section{CONFLICTS OF INTEREST}

The authors declare no conflict of interest and received no funding.

\section{REFERENCES}

1. Semih, Ö. and Yildiz, K. 2005. Analysis of Vitamins for the Health, Pharmaceutical and Food Sciences. In: Methods of Analysis of Food Components and Additives (Semih Otles Ed.), CRC press, Taylor and Francis Group, Florida, USA. pp. $159-178$

2. Treadwell, B.V. 2003. The Eight Faces of Vitamin E. Juvenon Health J. 2, 9.

3. Psomiadou, E., Tsimidou, M. and Boskou, D. 2000. $\alpha-$ Tocopherol content of greek virgin olive oils. J. Agric. Food Chem. 48, 1770-1775.

4. Traber, M.G. 2000.Vitamin E. In J. W. Erdman, I. A. MacDonald \& S. H. Zeisel (Eds.), Present Knowledge in Nutrition. Oxford: Wiley-Blackwell, Vol. 14, pp. 383-397.
5. Zou, L. and Akoh, C.C. 2015. Antioxidant activities of annatto and palm tocotrienol-rich fractions in fish oil and structured lipid-based infant formula emulsion. Food Chem. 168, 504-511.

6. Tiwari, U. and Cummins, E. 2009. Nutritional importance and effect of processing on tocols in cereals. Trends in Food Sci. Technol. 20, 511-520.

7. Aggarwal, B.B., Sundaram, C., Prasad, S and Kannappan, R. 2010. Tocotrienols, the vitamin $\mathrm{E}$ of the $21^{\text {st }}$ century: it's potential against cancer and other chronic diseases. Biochem. Pharmacol. 80, 1613-1631.

8. Hammond, E.W. 2003. Vegetables and oils composition and analysis. In: Encyclopedia of Food Sciences and Nutrition (Caballero B, Tugo LC, Finglas PM, Eds.). Elsevier Science Ltd. pp. 5916-5921.

9. Amaral, J.S., Casal, S., Torres, S., Seabra, D. and Oliveira M.B.P.P. 2005. Simultaneous determination of tocopherols and tocotrienols in hazelnuts by normal phase chromatographic method. Analyst Sci. 21, 1545-1548.

10. Rader, J.I., Weaver, C.M., Patrascu, L., Ali, L.H. and Angyal, G. 1997. -Tocophero1, total vitamin A and total fat in margarines and margarine-like products. Food Chem. 58, 313-379.

11. Tangolar, S.G., Ozogul, E., Tangolar, S. and Yagmur, C. 2011. Tocopherol content in fifteen grape varieties obtained using a rapid phase high performance chromatography method. J. Food Comp. Anal. 24, 481-486.

12. Mousavi, K., Shoeibi, S. and Ameri, M. 2012. Effects of storage condition and PET packaging on quality of edible oils in Iran. Adv. Environ. Biol. 6, 694-701.

13. Angaye, S.S. and Maduelosi, N.J. 2015. Comparative study of the physiochemical properties of some refined vegetable oils in mile one market and some departmental store in PortHarcourt, River state. Food Sci. Quality Management, 39, 1619

14. Aidos J., Lourenclo S., Padt, A., Luten J.B. and Boom, R. M. 2002. Stability of crude Herring oil produced from fresh byproducts; Influence of temperature during storage. J. Food Sci. 67, 3314-3320.

15. Fekarurhobo, G.K., Obomanu, F.G. and Maduelosi J.N. 2009. Effects of Short-term Exposure to sunlight on the quality of some Edible vegetable oils. Res. J. Appl. Sci. 4, 152-156.

16. Choe, E. and Min, D.B. 2006. . Mechanisms and factors for edible oil oxidation. Com. Rev. Food Sci. Food Safety, 5, 169-186.

17. Parcerisa, J., Casals, I., Boatella, J., Codony, R. and Rafecas, M. 2000. Analysis of olive and hazelnut oil mixtures by highperformance liquid chromatography-atmospheric pressure chemical ionisation mass spectrometry of triacylglycerols and gas-liquid chromatography of non-saponifiable compounds (tocopherols and sterols). J. Chromatogr. A. 881, 149-158.

18. Melchert, H.U and Pabel, E. 2000. Quantitative determination of R-, â-, ç-, and ä-tocopherols in human serum by high-performance liquid chromatography and gas chromatography-mass spectrometry as trimethylsilyl derivatives with a two-step sample preparation. $J$. Chromatogr. A. 896, 209-215.

19. Lee, Y.Y., Park, H.I., Lee, C.K., Kim, S.L., Hwang, T.Y., Choi, M.S., Kwon, Y.U., Kim, W.H., Lee, S.C. and Kim, Y.H. 2012. Comparing extraction methods for the determination of tocopherols and tocotrienols in seeds and germinating seeds of soybean transformed with OsHGGT. $J$. Food Comp. Anal. 27, 70-80.

20. Slavin, M. and Yu, L. 2012. A single extraction and high performance liquid chromatography procedure for 
simultaneous analysis of phytosterols, tocopherols and lutein in soybeans. Food Chem. 135, 2789-2795.

21. Habib, H., Kamal, H., Ibrahim, W.S. and Dhaheri, A.S.A. 2013. Carotenoids, fats soluble vitamins and fatty acid profile of 18 varieties of date seed oil. Ind. Crops. Prod. 42, 567572.

22. Gimeno, E., Castelotte, A.I., Lamuela-Raventos, R.M., Torre, M.C. and Lopez-Sabater, M.C. 2000. Rapid determination of vitamin $\mathrm{E}$ in vegetable oils by reversed phase high performance liquid chromatography. J. Chromatog A. 881, 251-254.

23. Gliszczyniska-Ewiglo, A. and Sikorska, E.2004. Simple reversed-phase liquid chromatography method for determination of tocopherols in edible plant oils. $J$. Chromatogr. A. 1048, 195-198.

24. Cunha, S.C., Amaral, J.S., Fernandes, J.O., Beatriz, M. and Oliveira, P.P. 2006. Quantification of Tocopherols and Tocotrienols in Portuguese Olive Oils Using HPLC with Three Different Detection Systems. J. Agric. Food Chem. 54, 3351-3356.

25. Andres, M.P.S., Otero, J. and Vera, S. 2011. High performance liquid chromatography method for simultaneous determination alpha-, gamma- and delta- tocopherol in vegetable oils in presence of hexadecyl trimethylammonium bromide/n-propanol in mobile phase. Food chem. 126, 14701474.

26. Cert, A., Moreda, W. and Perez-Camino, M.C. 2000. Chromatographic analysis of minor constituents in vegetable oils. J. Chromatog A. 881, 131-148

27. Abidi, S.L. and Mounts, T.L. 1997. Reversed-phase highperformance liquid chromatographic separations of tocopherols. J Chromatogr A. 782, 25-32

28. Tasioula-Margari, M. and Okoger, O. 2001. Simultaneous determination of phenolic compounds and tocopherols in virgin olive oil using HPLC and UV detection. Food Chem. 74, 377-383.

29. Jedlicka, A. and Klimes, J. 2005. Determination of water and fat soluble vitamins in different matrices using high performance liquid chromatography. Chem. Pap. 59, 202222.

30. Rupẽrez, F.J., Martỉn, D., Herrera, E. and Barbas, C. 2001. Chromatographic analysis of R-tocopherol and related compounds in various matrices. J. Chromatogr. A. 935, 4569.

31. Dionisi, F., Prodolliet, J. and Tagliaferri, E. 1995. Assessment of olive oil adulteration by reversed-phase highperformance liquid chromatography/amperometric detection of tocopherols and tocotrienols. J. Am. Oil Chem. Soc. 72, 1505-1511.

32. Association of Official Analytical Chemist (AOAC). 2000. Official method 965.33 peroxide value in oils and fats/ Pearson Composition and Analysis of Foods. 9, 641.
33. American Oil Chemists' Society (AOCS). 2003. Sampling and analysis of commercial fats and oils. AOCS Official Method AOCS Official Method, Ca 5a-40, Surplus Free Fatty Acids; AOCS Cold Spring Harbour: New York, NY, USA.

34. Association of Official Analytical Chemist (AOAC). 2000. Official method 920.160 saponification number of oils and fats/ I.U.P.A.C 2.202/ I.S.I Handbook of Food Analysis (111), p.78.

35. British Pharmacopoeia (BP). 2004. Cd., appendix XE, Iodine value, appendix $\mathrm{XG}$, Saponification value, appendix $\mathrm{XB}$ Acid value, appendix XF, Peroxide value.

36. Ekwu, F.C. and Nwagu, A. 2004. Effect of processing on the quality of cashew nut oils. J Sci. Agric. Food Technol. Environ. 4, 105-110.

37. Glucan, O. and Bedia, H. 2007. Antioxidant activities of Satureja cilicica essential oil in butter and in-vitro. J. Food Engineering. 79, 1391-1396.

38. Standard Organisation of Nigeria (SON). 2000. Standard Organization of Nigeria. Standards for edible refined palm oil and its processed, pp. 2-5

39. Frega, N., Mozzon, M. and Lercker, G. 1999. Free fatty acids on oxidative stability of vegetable oil. J. Am. Oil Chem. Soc. 76, 3, 325-329.

40. Zahir, E., Saheed, R., Hammed, M.A. and Yousuf, A. 2014. Study of physicochemical properties of edible oil and evaluation of frying oil quality by Fourier transform-infrared (FT-IR) spectroscopy. Arabian J. Chem. 10, 3870-3876.

41. Aluyor, E.O. and Ori-Jesu, M. 2008. The use of antioxidants in vegetable oils- a review. Afr. J. Biotechnol. 7, 4836-4842.

42. Gotor, A.A., Berger, M., Farkes, E., Labalette, F., Centis, S. and Calmon, A. 2007. Quantification of sunflower minor components by near infrared spectrophotometry (NIRS). Helia. 30, 183-189.

43. Jambunathan, R., Sridhar, R., Raghunath, K., Dwivedi, S.L. and Nigam, S.N. 1993. Oil quality characteristics and headspace volatiles of newly released groundnut (Arachis hypogaea L.) cultivars. J. Sci. Food Agric. 61, 23-30.

44. Reyes-Hernandez, J., Dibildox-Alvarado, E., Charo-Alonso, M. and Toro-Vazquez, J. 2007. Physicochemical and rheological properties of crystallized blends containing transfree and partially hydrogenated soyabean oil. J. Am. Oil Chem. Soc. 84, 1081-1093.

45. Institute of Medicine. 2000. Dietary Reference Intakes for vitamin C, vitamin E, selenium and carotenoids. Panel on dietary antioxidants and related compounds, National Academies Press, Washington DC (USA).

46. Philippi, S.T. 2008. Alimentacao Saudavel e a Piramide dos alimentos. In: Piramide dos Alimentos; Fundamentos basicos da Nutricao-2 ${ }^{\text {nd }}$ Edicao-Impresso (Phillipi S.T. Ed.), 1, pp. 3-9 